literature on weed killers as a guide to experimental work in this field. The extent of insecticide taint in wheat, the requirements of barley suitable for malting, especially for the British market, cold storage of fowls, fruit and other food products have all received attention, and physical conditions necessary for dechilling boxed poultry have been established which prevent the formation of condensate, a blemish which lowers the market quality.

THe Division of Physics and Engineering has been responsible for a good deal of standardization work in co-operation with the National Bureau of Standards, Washington. A 'reverberation chamber' has been built and used for measurements of the soundabsorbing properties of various kinds, building materials for Government departments and commercial firms. Apparatus completed during the year has enabled the Division to make thermal insulation tests on large samples of insulating materials, partitions and wall sections. An experimental investigation of the heating of railway refrigerator cars in winter has been completed, and in addition to aerial surveys the Division has been concerned with a number of aviation problems, including the development of a new type of aircraft ski. The Division of Research Information is being vigorously developed and the report also refers to conferences on forestry and fish culture and to the work of a number of associate committees, as well as to the assisted researches, for which grants amounting to 158,968 dollars were provided during the year, and to the 685 scholarships awarded to 385 persons, representing total grants of 570,053 dollars.

\section{Cancer Research in Australia}

THE report of the eighth Australian Cancer Conference, which was held in Canberra in April last, shows that it was a meeting well attended by representatives from Australasia. The recommendations of the Conference of the previous year appear to have been largely acceptable to the Commonwealth Government for, on September 24, 1936, a National Health and Medical Research Council was instituted by an Order in Council. The recommendation that the Commonwealth Government should appoint an Australian Cancer Commission did not, however, prove acceptable. Among other resolutions of the present year's Conference may be mentioned a recommendation that the Commonwealth Government should make available the sum of $£ 30,000$ annually for the purpose of establishing a permanent and reliable system of medical research. There is little doubt that a most lively interest is being taken officially by Australia in the subject of cancer among its population. This is reflected not only in public action but also in the publications which appear from time to time dealing with various aspects of this subject. "Physical Aspects of Radium and Radon Therapy" is a booklet prepared by Dr. C. E. Eddy, physicist-in-charge of the Commonwealth $\mathrm{X}$-ray and Radium Laboratory of the University of Melbourne, and Mr. T. H. Oddie, more especially for the use of radiotherapists and officers of local physical services. The booklet of sixty pages gives an extremely good account of the general physics of the substances and radiations used in radiotherapy together with an account of precautions necessary in using them. The relative advantages and disadvantages of radium and radon are also dealt with in a thoroughly explicit manner.

\section{Edible Birds Nests in the Philippines}

The edible nests of swiftlets, valued as a delicacy and as food for convalescents by the people of China, are built in limestone caves along the seashore in many parts of the Philippines. The export of the nests is in the hands of local Chinese merchants, and although accurate statistics are difficult to obtain it has been stated that the Netherlands Indies in 1927 exported 109,310 kilograms of nests valued at 822,913 guilders. In only one of the Philippine Islands, Bacuit, has an attempt been made to derive municipal revenue from the trade, when in 1927 the traditional ownership of the birds nest caves, which had existed for generations, was supplanted by municipal ownership and the annual leasing of the caves to the highest bidder. As a reply to this move, the Chinese dealers formed a ring so that the bidding, which reached 1,700 pesos in 1927 , had fallen in 1936 to 500 pesos, and in a footnote to a recent paper on the subject, Canuto G. Manuel states that as no bid at all was offered in 1937 , the caves have relapsed to the system of traditional ownership (Philippine J. Sci., 62, 379, March 1937). From Bacuit, approximately 500 kilograms or about 100,000 nests are exported annually, but poaching of nests is common, and attempts to limit the collecting with the view of conserving the stock have met with little success. Nest collecting, however, is a dangerous occupation, and the fact that some inaccessible caves are tenanted by the birds, which belong to the racial form, Collocalia francica germani, provides for the survival of the swiftlet.

\section{Literature of Food Investigation}

IN its report for 1936, the Food Investigation Board stated that a committee had been appointed to review both the scope and the form of its publication, "The Index to the Literature of Food Investigation". The first number of this journal appeared in 1929 and at present it covers about a hundred scientific and technical periodicals, each number containing upwards of 2,000 references, in the form of elaborated titles that indicate the scope of the papers indexed, but omit all experimental data. The original intention was that the "Index" should deal solely with the transport and storage of foodstuffs; it now tends to cover, however, the wider diverse field that lies between agriculture, or production, and nutrition, or the use of food for the maintenance of health. The first number of volume 7, which covers the literature published in 1934, has been issued ("Index to the 
Literature of Food Investigation" : 7, No. 1, March 1935. Compiled by Agnes Elisabeth Glennis, assisted by Gwen Davies. Pp. $371+$ xiii. (London : H.M. Stationery Office, 1937.) 5s. net); but it is hoped during the next twelve months to bring the "Index" up to date and to complete abstracts of the literature published in 1935 and 1936, which will form No. 2 of vol. 7, and vol. 8. Meanwhile the first number of vol. 9, containing abstracts of papers published during 1937 , is in preparation. The papers noted in the present number are arranged in fifteen sections, and there is an author index extending to twenty pages. The compiler gives a brief review of developments during 1933-34, selecting the following subjects : gas-storage of meat and fruit, storage of rice, eggs, anti-oxidants for fats and oils, and engineering. Attention is directed to the fact that 1934 was the centenary of the invention of the earliest continuous refrigerating machine, by Jacob Perkin, which used ether as refrigerant, and was the first real landmark in the history of modern refrigeration, so far as technique is concerned.

\section{Studies in Ancient Astronomy}

A sMalc collection of papers recently published in Meddelande Från Lunds Astronomiska Observatorium makes an interesting contribution to the study of the early history of astronomy. In an article entitled "Greek Cosmogony and Astronomy", Dr. K. Lundmark briefly traces the development of Greek astronomy from the first indications of some primitive astronomical knowledge found in the Homeric poems and in the work of Hesiod to the great work of the Alexandrine astronomers and mathematicians, culminating in the production of the "Almagest" in the second century A.D. A very useful synopsis for rapid reference is included of Greek astronomers and their contributions to astronomical ideas and observation. In another paper, P. Collinder studies the distribution of the birthplaces of the astronomers of antiquity. He remarks that the Hellenic peninsula itself produced but few in contrast with the west coast of Asia Minor, with Alexandria and the coast of southern Italy. It was, in fact, in the great merchant and shipping towns of these latter localities where the Greeks would best receive the importation of astronomical knowledge from the Babylonians, Egyptians and Phœenicians. A further contribution by $\mathbf{B}$. Svenonius describes his examination of certain rock sculptures found in Ostrogothie, Sweden. These engravings, which may date from the bronze age, include amongst the representations of men, animals, ships and primitive weapons, groupings of small cavities, which it is agreed represent groupings of the bright stars into constellations. M. Svenonius identifies the following constellations: the Great Bear, Cassiopeia, Perseus, Cepheus, Auriga, Orion and Leo. An examination by earlier Swedish investigators of similar rocks found in Bohuslän leads to the same general conclusion that the forms of several easily recognizable constellations were copied by some of the prehistoric watchers of the skies. In a supplementary note, A. Ohlmarks contributes remarks on these rock engravings and their relation to the history of early religious beliefs.

\section{Physics Research at Osaka}

THE volume of Collected Papers for 1936 from the physics section of the Faculty of Science of Osaka University includes 33 papers which have appeared in scientific periodicals between February 1936 and March 1937. The papers are in their covers as issued as reprints and are bound together with wire to constitute the volume, which is $10 \cdot 1$ in. $\times 7 \cdot 4 \mathrm{in} . \times 1$ in. Twenty-two of them are from the Proceedings of the Physico-Mathematical Society of Japan, five are Reports of Radio Research in Japan and two are from the Institute of Physical and Chemical Research, and five other institutions contribute a paper each. The papers from the Physico-Mathematical Society are nearly equally divided between problems of atomic structure and radiation, hydrodynamics and electricity. A table of contents is provided in which each paper is numbered and the number is printed on the right hand top corner of the cover of each so that reference is easy. The various publications from which the papers are reproduced appear to have very nearly the same size of page, slightly larger than that of the volume, except in one instance in which the page is 0.2 inch less wide. This inexpensive form of issuing collected papers seems to be on the increase.

\section{Films for Promoting International Understanding}

IN Film Progress of July, the Central Information Bureau for Educational Films, Ltd., announced the impending release of "Living in Wales", the second of its series of talking films designed to help the peoples of the world to gain a clearer insight into each other's lives and thereby to promote sympathetic mutual understanding. The first of the series, "Living in the Netherlands", is reported to have been well received both at The Hague and in London. "Living in Wales" was used at the Congrès Internationale de l'Enseignement Primaire et de l'Education Populaire to illustrate an address by Dr. G. H. Green of Aberystwyth on "The Cinematograph as a Means of Education for International Understanding". The paper emphasizes the fact that the educational film is not merely an additional means of illustrating or confirming what the teacher conveys through the medium of words, but also provides the closest possible approximation to real first-hand experience. It postulates four essentials for the success of films as instruments for promoting international understanding: an adequate supply of suitable trustworthy films, efficient machinery for production, distribution and publicity, comprehensive experiments and investigations into the technique of education by means of the film, and a centre for acquainting teachers not merely with the films and projectors available but also with all matters relating to films. The same issue of Film Progress announces the decision of Osaka City authorities to build an "Educational Movie Hall" at a cost of 500,000 yen for the benefit of primary school pupils. 